\title{
What elements of the patient-pharmacist relationship are associated with patient satisfaction?
}

This article was published in the following Dove Press journal:

Patient Preference and Adherence

21 September 2012

Number of times this article has been viewed

\section{Suliman A AIGhurair \\ Scot H Simpson \\ Lisa M Guirguis}

Department of Pharmacy Practice, University of Alberta, Edmonton, Canada
Correspondence: Lisa M Guirguis 3-17I Edmonton Clinic Health Academy, University of Alberta, I I 40587 Avenue, Edmonton, Alberta T6G IC9, Canada

$\mathrm{Tel}+\mathrm{I} 7804929693$

Fax +I 780492 I2I

Email lisa.guirguis@ualberta.ca
Background: Optimal medication management requires an effective relationship between the patient and health care professional. As pharmacists move from the traditional dispensing role to become more actively involved in patient care, factors influencing their relationship with patients need to be identified. A better understanding of these factors will facilitate more effective relationships.

Objective: To explore the effect of patient-perceived pharmacist expertise on relationship quality, self-efficacy, patient satisfaction, and relationship commitment.

Methods: This was a cross-sectional study conducted in five community pharmacies within the province of Alberta, Canada. A total of 500 patients were asked to complete a set of validated, self-administered questionnaires that measured perceived pharmacist expertise, relationship quality, self-efficacy, patient satisfaction, and relationship commitment. Hierarchical multiple regression was used to examine the associations between variables.

Results: A total of 112 surveys were returned. Internal consistency ranged from 0.86-0.92, suggesting good reliability, except for the relationship commitment scale. There was a significant, positive correlation between patient-perceived pharmacist expertise and quality of the relationship $(0.78 ; P<0.001)$. There were also significant, positive correlations between perceived expertise and patient satisfaction $(0.52 ; P<0.001)$ and relationship commitment $(0.47 ; P<0.001)$. These associations remained significant but the magnitude of correlation decreased when relationship quality was taken into account $(0.55 ; P<0.001$ and 0.56 ; $P<0.001$, respectively). On the other hand, there was no significant association between either patient-perceived pharmacist expertise or relationship quality and medication self-efficacy $(0.06$; $P=0.517$ and $0.10 ; P=0.292$, respectively).

Conclusion: Patient-perceived pharmacist expertise is an independent determinant of relationship quality, patient satisfaction, and relationship commitment. Relationship quality also appears to mediate the effect of perceived expertise on patient satisfaction and relationship commitment.

Keywords: relationship quality, pharmacist expertise, self-efficacy, relationship commitment, satisfaction

\section{Introduction}

The provider-patient relationship has become the topic of concern for many health care professionals. ${ }^{1}$ Building a good relationship between patients and their health care professionals is the essence of providing optimal care; in addition, this relationship is often thought to influence patient health outcomes. ${ }^{2}$ Good provider-patient relationships enable patients to ask questions, to share decisions with the providers, and to reach an agreement with their providers about the problem and the need for follow-up. ${ }^{3}$ 
Over the last two decades, the role of the pharmacist has changed. The new role has evolved from the traditional activity of dispensing medications to broader responsibilities of pharmaceutical care, ${ }^{4}$ but "pharmaceutical care requires a much more intimate and intensive relationship between the pharmacist and patient than simple pharmaceutical dispensing." ${ }^{5}$ Medication use is critical for treating and preventing diseases, ${ }^{6}$ however, the number of therapeutic agents that has been developed has increased dramatically over the last few decades. In addition, many patients require long-term and complex multitherapies. ${ }^{7}$ Research has shown improved patient health outcomes when pharmacists build therapeutic relationships with patients. ${ }^{8}$

Worley and Schommer reviewed the health sciences literature and created a pharmacy-specific model describing the factors that affect the patient-pharmacist relationship. ${ }^{9}$ The initial model found that patient-perceived pharmacist expertise and contact intensity predicted relationship quality, which in turn predicted relationship commitment. ${ }^{9}$ In other studies, they found that a minimum quality of relationship between the patient and pharmacist is required for the patient to commit to a relationship with the pharmacist. ${ }^{10,11}$ Worley and Hermansen-Kobulnicky also found an association between the quality of the patient-pharmacist relationship and the ability of diabetes patients to manage their own medications. ${ }^{12}$ In this study, patient satisfaction was measured as a component of the relationship quality construct together with patient trust and not as a separate construct.

Patient satisfaction is an important indicator of the quality of health care services and is an important predictor of maintaining a relationship with the health care provider and of adhering to a medication regimen. ${ }^{13}$ Satisfaction has been conceptualized differently over the last 15 years and has been characterized as a complex construct. ${ }^{14-16}$ Satisfaction with pharmacy services has been shown to be high with general pharmacy, specific interventions, and advanced practice skills. ${ }^{17,18}$ The contributors to this high level of satisfaction are not known, although it is hypothesized that this is due to low expectations. ${ }^{17}$ Kassam et al developed an anchored measure of patient satisfaction to address this situation..$^{14,19}$ Patients were asked to rate the care "they would expect at any pharmacy" and for "what they would expect in this pharmacy" to measure both expectations and satisfaction for specific items. This tool could be adapted to reflect the services provided to patients in community pharmacy.

Self-efficacy is a useful framework to understand and explain patient health behaviors and has been identified as a determinant of understanding instructions for taking medications and of adhering to medication regimens. ${ }^{20-22}$ Many clinical outcomes may be attributed to pharmacists, patients, physicians, and other health care professionals' care. However, because pharmacists are medication experts, it is anticipated that medication self-efficacy would result from the pharmacists' intervention. This research will explore whether there is a relationship between patient self-efficacy of medication use and quality of the relationship with the pharmacist.

In the current study, the Worley model was updated. The study proposed to explore the relationship between patientperceived pharmacist expertise and relationship quality with a new construct of medication self-efficacy (ie, taking medications and learning about medications self-efficacy) and a new specific robust measure of patient satisfaction. The aim was to improve an understanding of how to enhance patientpharmacist relationships with these new constructs.

The overall objective of this study was to explore the associations between patients' perceptions about patients' relationships with their pharmacists and the association of the relationship with medication self-efficacy, patient satisfaction, and relationship commitment to pharmacists in a sample of adult patients in the province of Alberta, Canada. Furthermore, the internal consistency of surveys in the current patient population was examined.

This study aimed to answer the following questions:

a) Are patient-perceived pharmacist expertise and relationship quality associated with patient satisfaction?

b) Are patient-perceived pharmacist expertise, relationship quality, and patient satisfaction associated with medication self-efficacy?

c) Are patient-perceived pharmacist expertise, relationship quality, and patient satisfaction associated with relationship commitment?

\section{Methods}

\section{Study design and procedure}

This survey-based, cross-sectional study was designed to explore patients' perceptions of the care they receive from pharmacists in the province of Alberta, Canada. The study was approved by the University of Alberta Health Research Ethics Board.

Patients from five pharmacies were recruited to examine the impact of quality of patient-pharmacist relationships in community pharmacies. Four pharmacies were identified in two major cities, and one pharmacy was in a rural town. Pharmacists at these pharmacies distributed surveys to 100 consecutive patients. An information letter attached to 
the front of the survey described the purpose, benefits, and expected duration (ie, 20 minutes) of the survey, as well as informed patients that their responses were confidential. Prepaid mail envelopes were provided. In order to reduce response bias and pharmacist burden, surveys were mailed directly to the research office.

Adult patients ( $\geq 18$ years of age) who were able to read and speak English and received either prescription or nonprescription services from the pharmacy were invited to participate in this study. Patients were excluded if they refused to participate in the study or could not provide informed consent.

To examine the independent associations between variables, the study controlled for demographics and pharmacy characteristics. The study aimed to examine the associations among the following variables: perceived expertise with relationship quality and self-efficacy; and relationship quality with self-efficacy, satisfaction, and relationship commitment. Assuming that responses from 15 participants would be required for each variable, ${ }^{23}$ the study needed to receive at least 75 completed surveys. Assuming a 20\% response rate, each of the five pharmacies was asked to hand out 100 surveys.

\section{Proposed model to be tested}

The proposed model tested in this study consists of predictor of relationship quality and outcomes of relationship quality as shown in Figure 1. The predictor of relationship quality was patient-perceived pharmacist expertise. The outcomes of the relationship quality were (a) medication self-efficacy, (b) patient satisfaction, and (c) relationship commitment. The model was also used to examine the relationship between patients' satisfaction with medication self-efficacy and patients' satisfaction with their commitment to their relationship with their pharmacist. The variables of the model tested in this study were identified based on evidence from patient-pharmacist relationship literature. ${ }^{9-11}$

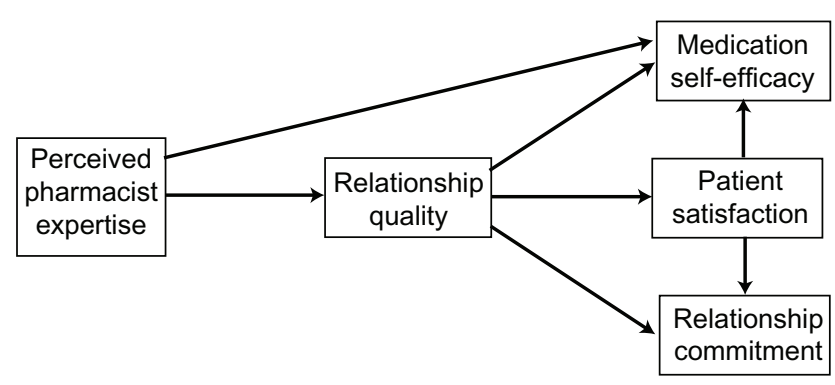

Figure I Pathway of the hypothesized model shows the relationships between study variables.

\section{Measures}

A combination of five validated questionnaires was used to measure the constructs of interest (Appendix 1); each questionnaire is described in further detail below. Patient demographic information was limited to age, to the length of time that the patient had been using the pharmacy, to the pharmacy store, and to the waiting time for one prescription to be prepared.

\section{Perceived pharmacist expertise}

Patient-perceived pharmacist expertise is the degree to which a patient believes the pharmacist has the knowledge, skills, and abilities necessary to help him or her. ${ }^{24}$ Patient-perceived pharmacist expertise has been shown to be an independent predictor of patient satisfaction and trust. ${ }^{25}$ Perceived pharmacist expertise was measured by a four-item scale (items 42-45) and rated on a five-point Likert scale from one (strongly disagree) to five (strongly agree). An example of items used in this scale is "my pharmacist is a knowledgeable source of prescription drug information."

\section{Relationship quality}

Relationship quality is "patient's perceptions of his or her provider's social exchange-based, affective qualities, including dimensions of caring, respect, and trustworthiness." The construct of relationship quality in this study has two dimensions: (a) patient trust in a pharmacist and (b) satisfaction with the pharmacist. ${ }^{9}$ The quality of the patient-pharmacist relationship was measured by an eightitem scale (items 46-53) and rated on a five-point Likert scale. Coding of item 48 "there are times when my pharmacist seems insincere" was reversed.

\section{Relationship commitment}

Relationship commitment can be defined as the likelihood that a patient will seek an interaction and maintain a longterm relationship with his or her pharmacist. ${ }^{25}$ Patients' commitment to their relationships to their pharmacists was measured by a three-item scale (items 54-56) and rated on a five-point Likert scale. Coding of item 56 "if a less expensive pharmacy opened near my present pharmacist, I would change pharmacies" was reversed.

\section{Medication self-efficacy}

Self-efficacy is defined as a patient's confidence in his or her ability to successfully execute a behavior. ${ }^{20}$ The Medication Understanding and Use Self-Efficacy scale, has two dimensions: (a) learning about medication and 
(b) taking medication. ${ }^{21}$ The Medication Understanding and Use Self-Efficacy scale has evidence for its validity and reliability. ${ }^{21}$ This scale was selected because it was brief, was not disease specific, and was intended to be used with patients of different health literacy levels. Responses were measured on a four-point Likert scale (one, strongly disagree; two, slightly disagree; three, slightly agree; and four, strongly agree); scores on the measure could range from four to $32 .{ }^{21}$

\section{Patient satisfaction}

Patient satisfaction is the degree to which patients' expectations, goals, and/or preferences are met by the health care provider and/or service. ${ }^{26}$ Patient satisfaction is a unique and multidimensional construct. ${ }^{27}$ Various frameworks have been used to conceptualize patient satisfaction with pharmacy services; for instance, patient satisfaction was measured as a single entity and linked with economic, clinical, and humanistic outcomes. ${ }^{28}$ In addition, other studies measured patient satisfaction as a construct that belongs to relationship quality. ${ }^{9}$ In a 2009 review, Naik Panvelkar et al concluded that pharmacy research lacks a robust measurement of patients' satisfaction in community pharmacy due to a lack of comprehensive theoretical frameworks and well-designed instruments. ${ }^{17}$ Kassam et al developed a new measure of patient satisfaction. This unique measure addresses the shortcomings of the previous surveys by contrasting patients' experiences and expectations about specific elements of patient care using 15 questions. ${ }^{14}$

The responses on the patient satisfaction scale were measured on a five-point Likert scale (one, strongly disagree; two, disagree; three, neutral; four, agree; and five, strongly agree). The same survey developed by Kassam et al was used in the current study, but two questions were added to capture the assessment and documentation activities and four questions that did not apply were removed. These modifications invalidated the prior psychometric properties but allowed for the measurement of expectations and satisfaction of items that were relevant to the sampled pharmacies.

Patient satisfaction was measured by calculating the difference between pairs of items from the two subscales (experience and expectation) and then taking the mean. The mean differences can range from negative four to four: negative scores indicate that patients' expectations were higher than their experiences, zero scores indicate an equal rating of both experiences and expectations, and positive scores indicate that patients' experiences were higher than their expectations.

\section{Data analysis}

The data were analyzed using SPSS ${ }^{\circledR} 17.0$ for Windows (IBM Corporation, Armonk, NY). Mean imputation was used to replace missing responses. The reliability of each subscale was tested by Cronbach's alpha. Means and standard deviations as well as sum of the scale items were calculated for all scales to allow for comparison with prior published literature and to facilitate understanding. Higher scores on the perceived pharmacist expertise scale, relationship quality scale, self-efficacy scale, and relationship commitment scale indicate patients believe that pharmacists have greater expertise, have greater trust in and satisfaction with pharmacists, are more confident to take and learn about medications, and have a stronger commitment to their relationships with the pharmacists, respectively.

Hierarchical multiple linear regression was used to examine the relationship between predictors and the dependent variables as in the research questions. Regression coefficients were tested for significance at an alpha level of 0.05. Mean imputation was used to replace missing responses.

Research questions were tested with blocks of variables. The order of entry of predictor variables reflects the hypothesized pathway shown in Figure 1. The model tested was based on evidence from the literature on patient-pharmacist relationships. The quality of the patient-pharmacist relationship has been shown to be influenced by patient-perceived pharmacist expertise; furthermore, perceived expertise and relationship quality were found to affect the likelihood of seeking future contact with the pharmacist. ${ }^{9}$ In addition, the quality of the patient-pharmacist relationship may enhance medication self-efficacy. ${ }^{12}$

Demographics (patient's age, the pharmacy store, length of time that the patient had been using the pharmacy, and waiting time for one prescription to be prepared) were used as control variables, and their relationship with dependent variables was assessed in the regression model. The first research question was tested with three blocks of variables. Demographics were entered in block one, perceived pharmacist expertise was entered in block two, and relationship quality was entered in block three. The second research question was tested with four blocks of variables. Blocks one, two, and three were entered as per the first research question, and patient satisfaction was entered in block four. The third research question was tested with four blocks of variables as in the second research question. The regression equations are given in Table 1.

Examination of the distributions of the perceived pharmacist expertise, relationship quality, satisfaction, and relationship 
Table I Regression equations

Regression model I: $Y_{P S}=X_{D G}+X_{P E}+X_{R Q}+e_{P S}$

Regression model 2: $Y_{\mathrm{SE}}=\mathrm{X}_{\mathrm{DG}}+\mathrm{X}_{\mathrm{PE}}+\mathrm{X}_{\mathrm{RQ}}+\mathrm{X}_{\mathrm{PS}}+\mathrm{e}_{\mathrm{SE}}$

Regression model 3: $Y_{R C}=X_{D G}+X_{P E}+X_{R Q}+X_{P S}+e_{R C}$

Abbreviations: e, error; $D G$, demographics, $P E$, perceived pharmacist expertise; $\mathrm{PS}$, patient satisfaction; RC, relationship commitment; RQ, relationship quality; $\mathrm{SE}$, self-efficacy; $X$, the value of the independent variable; $Y$, the predicted value of dependent variable.

commitment subscale scores showed that the data were suitable for hierarchical multiple regression analysis. Correlations that did not fit the assumptions for hierarchical multiple linear regression were not considered in the model.

To examine the mediation effect of relationship quality and patient satisfaction, the approach developed by Baron and Kenny (1986) was used to identify whether the mediators had complete, partial, or no mediation effect. ${ }^{29}$ This approach is based on conducting several simple regression analyses between variables through the following three steps: initial variable with the outcome, initial variable with the mediator, and mediator with the outcome. The final step involves conducting multiple regression analysis between all variables. The purpose of the first three steps is to identify whether there are significant relationships between variables. A difference between the unstandardized coefficients resulting from the first and the final step of zero indicates a full mediation effect; otherwise, it indicates a partial mediation effect.

\section{Results}

Of the 500 surveys given to patients, 112 surveys were returned, giving a response rate of $22.4 \%$. Twenty-one patients missed 33 items. Approximately two-thirds of the respondents were between 36 and 65 years of age, and $91(81 \%)$ of 112 respondents had used the same pharmacy for more than 1 year. One participant $(0.9 \%)$ was between 18 and 25 years old, and seven participants $(6.3 \%)$ were $\geq 76$ years as shown in Table 2 . All scales had good internal reliability (Cronbach's alpha $>0.85$ ) except for the relationship commitment scale (Cronbach's alpha $=0.430)$ as shown in Table 3 . The influence of all demographics was tested on the outcomes in the regression analysis of each research question. Those that had nonsignificant associations with the outcomes (patient's age, the name of the pharmacy, and length of time for a prescription to be prepared) were excluded from the analysis. Preliminary analysis of the data using SPSS output, histograms, and scatter plots revealed no serious violations of the assumptions of linearity of the underlying distributional assumptions of the residuals of the dependent variables
Table 2 Demographics

n (\%)

\begin{tabular}{|c|c|}
\hline \multicolumn{2}{|l|}{ Age (years) } \\
\hline $18-25$ years & I (0.9\%) \\
\hline $26-35$ years & $10(8.9 \%)$ \\
\hline $36-45$ years & $24(21.4 \%)$ \\
\hline $46-55$ years & $32(28.6 \%)$ \\
\hline $56-65$ years & $19(17.0 \%)$ \\
\hline 66-75 years & $19(17.0 \%)$ \\
\hline$\geq 76$ years & $7(6.3 \%)$ \\
\hline \multicolumn{2}{|c|}{ Pharmacy patronage } \\
\hline First time & I (0.9\%) \\
\hline $0-6$ months & $5(4.5 \%)$ \\
\hline 6 months-I year & $15(13.4 \%)$ \\
\hline $\mathrm{I}-5$ years & $69(61.6 \%)$ \\
\hline Other & $22(19.6 \%)$ \\
\hline \multicolumn{2}{|c|}{ Waiting time for one prescription } \\
\hline $0-2$ minutes & 0 \\
\hline $3-5$ minutes & I $(0.9)$ \\
\hline $6-10$ minutes & $40(35.7)$ \\
\hline II-15 minutes & $41(36.6)$ \\
\hline $16-20$ minutes & $15(13.4)$ \\
\hline $21-25$ minutes & $5(4.5)$ \\
\hline 26-30 minutes & $4(3.6)$ \\
\hline $31-45$ minutes & $2(2.8)$ \\
\hline $46-60$ minutes & $2(2.8)$ \\
\hline$>61$ minutes & $2(2.8)$ \\
\hline \multicolumn{2}{|c|}{ Expected time to talk with pharmacist } \\
\hline $0-2$ minutes & $28(25)$ \\
\hline $3-5$ minutes & $50(44.6)$ \\
\hline $6-10$ minutes & $27(24.1)$ \\
\hline II-15 minutes & I (0.9) \\
\hline $16-20$ minutes & $2(1.8)$ \\
\hline $21-25$ minutes & 0 \\
\hline 26-30 minutes & 0 \\
\hline $31-45$ minutes & 0 \\
\hline $46-60$ minutes & I (0.9) \\
\hline$>61$ minutes & $3(2.7)$ \\
\hline
\end{tabular}

for models one and three. For model two, the data showed a curvilinear relationship with the predicted dependent variable (self-efficacy), hence violating the assumption of normality and homoscedasticity; therefore, the association between patient-perceived pharmacist expertise, relationship quality, patient satisfaction, and self-efficacy could not be assessed.

Simple correlation values of all variables in the analysis are shown in Table 3 together with their significance values. Results showed no high association $(>0.8)$ among the predictors (ie, multicollinearity did not violate the regression assumptions).

In regression model one, the predictors of patient satisfaction were assessed (Table 4). In the first step, the inclusion of the length of time that a patient had used a pharmacy was statistically significant and showed a small increase 
Table 3 Correlations matrix for the variables of the study and internal consistency of each scale $(n=I I 2)$

\begin{tabular}{|c|c|c|c|c|c|c|c|c|c|c|}
\hline & & I & 2 & & 3 & 4 & 5 & & 6 & 7 \\
\hline Patients' age & I & I & & & & & & & & \\
\hline Duration of patronage & 2 & $0.25 *$ & 1 & & & & & & & \\
\hline \multicolumn{11}{|l|}{ one prescription } \\
\hline \multicolumn{10}{|l|}{ of pharmacist } & \\
\hline Relationship quality & 5 & 0.03 & $0.24 *$ & & -0.02 & $0.78^{*}$ & 1 & & & \\
\hline Relationship commitment & 6 & 0.05 & $0.23^{*}$ & & -0.04 & $0.47^{*}$ & $0.56^{*}$ & & 1 & \\
\hline Patient satisfaction & 7 & 0.02 & $0.19 *$ & & 0.11 & $0.52 *$ & $0.55^{*}$ & & 0.37 & I \\
\hline Self-efficacy & 8 & 0.16 & -0.02 & & 0.051 & 0.06 & 0.10 & & 0.06 & $0.19 *$ \\
\hline \multirow[t]{2}{*}{ Scale } & \multirow[t]{2}{*}{ Items } & \multicolumn{4}{|c|}{ Sum of scale items } & \multicolumn{4}{|c|}{ Mean of scale items } & \multirow[t]{2}{*}{ Cronbach's $\alpha$} \\
\hline & & Mean & SD & Min & Max & Mean & SD & Min & Max & \\
\hline Self-efficacy** & 8 & 29.99 & 3.22 & 12.00 & 32.00 & 3.75 & 0.40 & 1.50 & 4.00 & 0.86 \\
\hline Patients' expectations ${ }^{\dagger}$ & 15 & 58.11 & 8.20 & 31.00 & 75.00 & 3.87 & 0.55 & 2.00 & 5.00 & 0.87 \\
\hline Patients' experiences ${ }^{\dagger}$ & 15 & 51.00 & 11.22 & 22.00 & 75.00 & 3.40 & 0.75 & 1.50 & 5.00 & 0.92 \\
\hline $\begin{array}{l}\text { Perceived expertise of } \\
\text { pharmacist }^{\dagger}\end{array}$ & 4 & 17.65 & 2.17 & 10.00 & 20.00 & 4.41 & 0.54 & 2.50 & 5.00 & 0.86 \\
\hline Relationship-quality ${ }^{\dagger}$ & 8 & 34.91 & 4.55 & 18.00 & 40.00 & 4.36 & 0.57 & 2.25 & 5.00 & 0.89 \\
\hline Relationship commitment $^{\dagger}$ & 3 & 12.54 & 2.04 & 7.00 & 15.00 & 4.18 & 0.68 & 2.30 & 5.00 & 0.43 \\
\hline
\end{tabular}

Notes: *Correlation is significant $(P<0.05)$; **scale of I: strongly disagree, 2: slightly disagree, 3: slightly agree, and 4: strongly agree; †scale of I: strongly disagree, 2: disagree, 3: neutral, 4: agree, and 5 : strongly agree.

Abbreviations: min, minimum; max, maximum; SD, standard deviation.

(3.6\%) in the proportion of variance in patient satisfaction $\left(\mathrm{R}^{2}\right.$ change $=0.036 ; \mathrm{F}$ change $\left.[1,110]=4.10 ; P<0.05\right)$. In the second step, patient-perceived pharmacist expertise explained an additional $23 \%$ of the variance in patient satisfaction $\left(\mathrm{R}^{2}\right.$ change $=0.23 ; \mathrm{F}$ change $[2,109]=34$; $P<0.001)$. In the third step, the quality of relationship explained an additional $5 \%$ of the variance of patient satisfaction $\left(\mathrm{R}^{2}\right.$ change $=0.05 ; \mathrm{F}$ change $[3,108]=8.82$; $P<0.005)$. Based on the theoretical model, patientperceived pharmacist expertise explained the greatest proportion of patient satisfaction. Table 4 reports the values of beta for independent variables included in each step of the procedure together with their significance values.

In regression model three, the predictors of relationship commitment were assessed (Table 5). The length of time that patients had used a particular pharmacy was entered in variable block one and explained only $5 \%$ of the variance in relationship commitment $\left(\mathrm{R}^{2}\right.$ change $=0.05 ; F$ change $[1,110]=6.18 ; P<0.05)$. After controlling for the length of time a patient had been using the pharmacy, patientperceived expertise explained an additional $17 \%$ of variance in relationship commitment $\left(\mathrm{R}^{2}\right.$ change $=0.17$; F change $[2,109]=23.41 ; P<0.001)$. In addition, relationship quality explained $11 \%$ of variance in relationship commitment $\left(\mathrm{R}^{2}\right.$ change $=0.11 ; \mathrm{F}$ change $\left.[3,108]=16.83 ; P<0.001\right)$. Patient satisfaction explained only $1 \%$ of variance in relationship commitment $\left(\mathrm{R}^{2}\right.$ change $=0.01 ; \mathrm{F}$ change $[4,107]=0.81$; $P=0.370$ ). Pharmacist expertise explained the greatest amount of variance in relationship commitment followed by relationship quality. The values of beta for independent variables included in each step of this procedure together with their significance values are reported in Table 5 .

Table 4 Hierarchical regression analysis for variables predicting patient satisfaction $(n=112)^{\dagger}$

\begin{tabular}{|c|c|c|c|c|c|c|c|c|c|}
\hline \multirow[t]{2}{*}{ Variable } & \multicolumn{3}{|c|}{ Step I } & \multicolumn{3}{|c|}{ Step 2} & \multicolumn{3}{|c|}{ Step 3} \\
\hline & B & SE B & $\beta$ & B & SE B & $\beta$ & B & SE B & $\beta$ \\
\hline Duration of patronage & 0.17 & 0.09 & $0.19 *$ & -0.01 & 0.08 & -0.01 & 0.01 & 0.08 & 0.02 \\
\hline Perceived expertise & & & & 0.69 & 0.12 & $0.52 * *$ & 0.30 & 0.18 & 0.22 \\
\hline Relationship quality & & & & & & & 0.46 & 0.16 & $0.36 * *$ \\
\hline $\mathrm{R}^{2}$ & & 0.04 & & & 0.27 & & & 0.32 & \\
\hline$F$ for change in $R^{2}$ & & $4.00 *$ & & & $34.00 * *$ & & & $8.15 * *$ & \\
\hline
\end{tabular}

Notes: Data were checked and met assumptions for linearity, independence of errors, normality, and homoscedasticity; $* P<0.05 ; * * P<0.01 ;{ }^{\dagger}$ patient satisfaction $=-3.873+$ 0.272 perceived expertise +0.490 relationship quality +0.507 .

Abbreviations: $\beta$, standardized regression coefficient; $B$, unstandardized regression coefficient; SE, standard error. 
Table 5 Hierarchical regression analysis for variables predicting relationship commitment $(\mathrm{n}=1 \mathrm{I} 2)^{\dagger}$

\begin{tabular}{|c|c|c|c|c|c|c|c|c|c|c|c|c|}
\hline \multirow[t]{2}{*}{ Variable } & \multicolumn{3}{|c|}{ Step I } & \multicolumn{3}{|c|}{ Step 2} & \multicolumn{3}{|c|}{ Step 3} & \multicolumn{3}{|c|}{ Step 4} \\
\hline & B & SE B & $\beta$ & B & SE B & $\beta$ & B & SE B & $\beta$ & B & SE B & $\beta$ \\
\hline Duration of patronage & 0.20 & 0.08 & $0.23 *$ & 0.06 & 0.08 & 0.06 & 0.10 & 0.08 & 0.10 & 0.10 & 0.08 & 0.10 \\
\hline Perceived expertise & & & & 0.56 & 0.12 & $0.44 * *$ & 0.03 & 0.17 & 0.02 & 0.01 & 0.17 & 0.004 \\
\hline Relationship quality & & & & & & & 0.62 & 0.15 & $0.52 * *$ & 0.59 & 0.16 & $0.49 * *$ \\
\hline Patient satisfaction & & & & & & & & & & 0.10 & 0.09 & 0.10 \\
\hline $\mathrm{R}^{2}$ & & 0.05 & & & 0.22 & & & 0.33 & & & 0.33 & \\
\hline$F$ for change in $R^{2}$ & & $6.18^{*}$ & & & 23.40 ** & & & $16.83 * *$ & & & 1.00 & \\
\hline
\end{tabular}

Notes: Data were checked and met assumptions for linearity, independence of errors, normality, and homoscedasticity; $* P<0.05$; $* * P<0.01$; ${ }^{\dagger}$ relationship commitment $=$ $1.422+0.075$ perceived expertise +0.486 relationship quality +0.119 patient satisfaction +0.562 .

Abbreviations: $\beta$, standardized regression coefficient; $B$, unstandardized regression coefficient; SE, standard error.

The final model with the statistically significant associations is shown in Figure 2.

The results of testing the mediation effect showed that quality of relationship had a partial mediation effect between patient-perceived pharmacist expertise and patient satisfaction; in addition, it had a partial mediation effect between patient-perceived pharmacist expertise and relationship commitment. Figure 3 shows the regression coefficients for mediation between the study variables.

\section{Discussion}

In the sample of patients recruited from the five pharmacies in the province of Alberta, patient-perceived pharmacist expertise was an independent determinant of relationship quality, patient satisfaction, and relationship commitment. All scales showed good reliability, except for the relationship commitment scale as measured by Cronbach's alpha. In multivariate models, patient satisfaction and relationship commitment were related to patient-perceived pharmacist expertise and relationship quality. However, patient-perceived pharmacist expertise predicted more of the variance in patient satisfaction and relationship commitment than relationship quality. Relationship quality mediated the effect of perceived

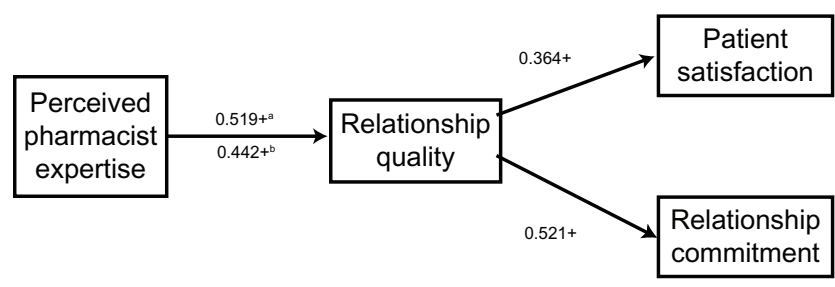

Figure 2 The association between predictors and outcomes when controlling the duration of patient patronage to pharmacy.

Notes: ${ }^{+} P<0.05$; ${ }^{a}$ the standardized regression coefficient for testing the perceived expertise of the pharmacist as a predictor for patient satisfaction; b the standardized regression coefficient for testing the perceived expertise of the pharmacist as a predictor for relationship commitment. expertise on patient satisfaction and relationship commitment The relationship of self-efficacy with other variables could not be assessed due to a violation of regression assumptions.

The current findings were consistent with the findings from previous research. Worley and Schommer studied patients' perspective of pharmacist expertise, relationship quality, and relationship commitment with the pharmacist. ${ }^{9}$ They found that the relationship quality mediated the relationship between patient-perceived pharmacist expertise and relationship commitment; ${ }^{9}$ in addition, patient-pharmacist relationship quality was highly correlated with relationship commitment. ${ }^{9-11}$ These findings suggest that patients viewed the pharmacist's expertise as an important factor for sustaining a relationship with the pharmacist; however, a level of trust and satisfaction (relationship quality) must be developed between patient and pharmacist before a committed relationship can be built.

Patient-perceived pharmacist expertise significantly predicted more variance in patient satisfaction than relationship quality. The current findings also confirmed the importance of relationship quality as a mediator between patient-perceived pharmacist expertise and satisfaction. These findings suggest that patient evaluations of the pharmacist's competence
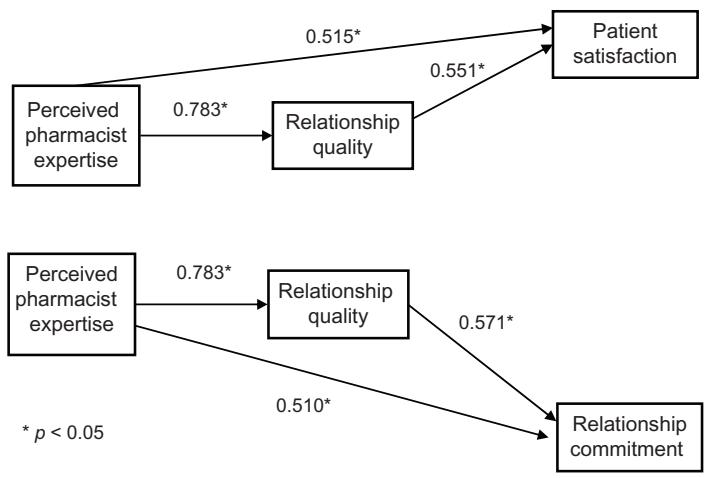

Figure 3. The partial mediation relationship between the study variables. 
influence patient satisfaction; in addition, in order to achieve patient satisfaction with pharmacist expertise, a good relationship must be built between the patient and pharmacist. Perepelkin recently found that the respondents with lower levels of education placed more importance on pharmacist expertise and the relationship with the pharmacist than those with a higher education. ${ }^{30}$ Future studies should include patients' level of education.

Previous research suggested that patients commonly request information on adverse effects, basic instructions, and drug interactions. ${ }^{31}$ In the current study, the following patients' perceptions of pharmacist expertise were measured: ability to answer questions, ability to explain medication use, and ability to provide information regarding potential side effects of the medication. Patients evaluated the pharmacist's expertise based on the pharmacist's provision of medication information; thus the provision of medication information was an important factor for building and sustaining patient relationships.

Other findings from patient-physician relationship research were similar to the current findings. In one study, patients were able to evaluate physician technical competence; additionally, patients' perceptions of physician competence influenced patients' trust in physicians. ${ }^{32}$ In another study, patient-perceived physician expertise, exchange of information, patients' trust, and the quality of the relationship significantly influenced patient satisfaction. ${ }^{33}$

The relationship of self-efficacy with perceived expertise, relationship quality, and patient satisfaction in the second model could not be analyzed due to the failure to meet the regression assumptions. This failure could be attributed to the measurement of self-efficacy, which appeared to have a ceiling effect with limited variance to explore relationships with other variables. The average age of patients was over 46 years old, and most had visited the same pharmacy for more than 1 year. This might imply that they were obtaining medications for regular chronic conditions where they potentially had high self-efficacy. Other researchers have found a positive association between patient-pharmacist relationship and self-efficacy for patients with type 2 diabetes and older adults. ${ }^{12}$ The patientphysician relationship (trust) had a significant positive association with patients' self-efficacy expectations in patients with type 2 diabetes. ${ }^{34}$ Keshishian et al found patients had better quality relationships with their physicians than their pharmacists, and only the relationship with their physicians predicted self-efficacy for medication management. ${ }^{35}$ The findings from previous studies about the association between relationship quality and self-efficacy were based on the measurement of patient self-efficacy toward medication taking or medication management; however, patient self-efficacy was also measured in the current study to learn about medications. Further research may consider the impact of the patient-pharmacist relationship on patient self-efficacy with attention to the selection of an appropriate self-efficacy measure.

Patient-perceived pharmacist expertise predicted a greater proportion of the variance in relationship commitment than patient satisfaction. This result could be attributed to the theoretically established order of entry in the regression analysis. Another possible explanation of this result could be attributed to the measurement of satisfaction. Patients are generally satisfied with pharmacists. ${ }^{17}$ In contrast, a service gap was found in the current study by using an anchored measure of patient satisfaction. Pharmacists may have been challenged by many daily constraints (eg, workload and time constraints). Similar to other research that used this survey tool, pharmacists were not meeting patient expectations when providing patient care activities. ${ }^{19}$ This lower level of satisfaction may explain the lower explanatory power of patient satisfaction in the current research.

Other results from patient-physician relationships research were partially consistent with the current findings. ${ }^{36,37}$ They suggested that both physician medical competence and patient satisfaction promoted long-term relationships; ${ }^{36,37}$ therefore, the variation from the current results of patientpharmacist relationships could be attributed to the differing components of the patient satisfaction construct that was measured or the differing quality of physician-patient relationships.

It was identified in this and previous studies that patientperceived pharmacist expertise and patient-pharmacist relationship quality are important factors in building patient satisfaction and forming a committed relationship with the pharmacist. Although patients viewed pharmacist expertise as an important predictor for their satisfaction and relationship commitment with a pharmacist, the quality of the relationship is a contributing factor and requires pharmacist attention.

\section{Strengths and limitations}

This study has several strengths and limitations. The survey included instruments with established psychometric properties and was self-administered to minimize bias associated with the presence of the pharmacist. This study explored patients' perceptions with no disease restrictions; hence, 
findings could be useful to understand the views of a sample with different conditions.

Results of this study should be interpreted within the context of the following limitations. First, the survey was limited to English-speaking patients or clients only; in addition, reading assessment was not performed for participants. Second, the results from the relationship commitment scale should be interpreted with caution due to the low internal consistency of the scale; however, the scale has shown an acceptable internal consistency in other studies. ${ }^{9}$ Third, patient self-report bias should also be considered because some patients may be reluctant to report their low satisfaction with pharmacists due to certain factors, such as social desirability. Fourth, sampling technique used in this study was convenience sampling, the number of patients who refused to take the survey was not collected, and the response was low; therefore, the results from this sampling cannot be generalized to the whole population. Likewise, the selection of pharmacists and pharmacies was not random; findings also cannot be generalized to the whole population. Finally, patient demographics in this study were limited to age, length of time a patient had used a particular pharmacy, the pharmacy store, and waiting time for one prescription to be prepared; therefore, the impact of gender, level of education, availability of drug coverage insurance, and long-term versus new patients, and prescriptions for chronic versus acute diseases were not explored.

\section{Pharmacy practice implications}

The results of this study have important implications for pharmacy practice, particularly because there were some consistencies with the findings of previous studies. This study identified the importance of patient-perceived pharmacist expertise and relationship quality in developing patient satisfaction and committed patient-pharmacist relationships. Community pharmacists should strive to show patients that they provide useful information and take responsibility for their health care; in addition, they should exhibit a professional attitude to reflect their expertise. These efforts can increase patient trust and satisfaction in the pharmacist and are important indicators from the patients' perspective for developing a committed relationship. Pharmacy practice research should measure patients' satisfaction over time for a better understanding of patients' perceptions about the care they receive from a pharmacist. Results from research into patients' perceptions of pharmacist expertise and relationship quality should be integrated into pharmacy school curriculum to better prepare students for patient care.

\section{Recommendation for future research}

Longitudinal data collection is needed in future research to study the influence of perceived pharmacist expertise, relationship quality, and patient satisfaction on patient selfefficacy. In addition, future studies are needed to identify other factors that are important in building relationship quality and relationship commitment between patient and pharmacist and to determine whether these survey instruments are sensitive to change. Ultimately, research is required to elucidate the pathway between these constructs and patient medication and health outcomes.

\section{Conclusion}

Patient-perceived pharmacist expertise is an important determinant of patient satisfaction and relationship commitment with the pharmacist. The quality of the relationship predicted satisfaction and commitment but was less important than the patient-perceived expertise of the pharmacist. Increased quality of the patient-pharmacist relationship and pharmacist expertise together were associated with enhanced patient satisfaction and relationship commitment, which may ultimately lead to better patient medication outcomes.

\section{Acknowledgments}

Mr Suliman AlGhurair would like to acknowledge the Medical Services Directorate of Saudi Armed Forces for supporting his graduate study.

\section{Disclosure}

The authors report no conflicts of interest in this work.

\section{References}

1. Hermansen CJ, Wiederholt JB. Pharmacist-patient partnership development in an ambulatory clinical setting. Health Commun. 2001;13(3):307-325.

2. Molassiotis A, Morris K, Trueman I. The importance of the patientclinician relationship in adherence to antiretroviral medication. Int $J$ Nurs Pract. 2007;13(6):370-376.

3. Stewart MA. Effective physician-patient communication and health outcomes: a review. CMAJ. 1995;152(9):1423-1433.

4. Berger B. Building an effective therapeutic alliance: competence, trustworthiness, and caring. Am J Hosp Pharm. 1993;50(11):2399-2403.

5. Sleath B. Pharmacist patient relationships: authoritarian, participatory, or default? Patient Educ Couns. 1996;28(3):253-263.

6. Tarn DM, Hertigae J, Paterniti DA, Hays RD, Kravitz RL, Wenger NS. Physician communication when prescribing new medications. Arch Intern Med. 2006;166(17):1855-1862.

7. Broemeling AM, Watson DE, Prebtani F. Population patterns of chronic health conditions, co-morbidity and healthcare use in Canada: implications for policy and practice. Healthc Q. 2008;11(3):70-76.

8. Pringle J, Melczak M, Aldridge A, Snyder M, Smith R. Medication adherence and its relationship to the therapeutic alliance: results from an innovative pilot study within a community pharmacy MTM practice. Innov Pharm. 2011;2(1): Article 33.1-16. 
9. Worley MM, Schommer JC. Pharmacist-patient relationships: factors influencing quality and commitment. J Social Adm Pharm. 1999; 16(3-4):157-173.

10. Worley-Louis MM, Schommer JC. Pharmacists' therapeutic relationships with older adults: the impact of participative behavior and patientcenteredness on relationship quality and commitment. J Social Adm Pharm. 2002;19(5):180-189.

11. Worley MM. Testing a pharmacist-patient relationship quality model among older persons with diabetes. Res Social Adm Pharm. 2006; 2(1): $1-21$

12. Worley MM, Hermansen-Kobulnicky CJ. Outcome and self-efficacy expectations for medication management of patients with diabetes: influence of the pharmacist-patient relationship. J Am Pharm Assoc. 2008;48(5):621-631.

13. Schommer JC, Kucukarslan SN. Measuring patient satisfaction with pharmaceutical services. Am J Health Syst Pharm. 1997;54(23): 2721-2732.

14. Kassam R, Collins JB, Berkowitz J. Developing anchored measures of patient satisfaction with pharmaceutical care delivery: experiences versus expectations. Patient Prefer Adherence. 2009;3:113-122.

15. Larson LN, Rovers JP, MacKeigan LD. Patient satisfaction with pharmaceutical care: update of a validated instrument. J Am Pharm Assoc. 2002;42(1):44-50.

16. Ried LD, Wang F, Young H, Awiphan R. Patients' satisfaction and their perception of the pharmacist. J Am Pharm Assoc. 1999;39(6): 835-842.

17. Naik Panvelkar P, Saini B, Armour C. Measurement of patient satisfaction with community pharmacy services: a review. Pharm World Sci. 2009;31(5):525-537.

18. Krass I, Delaney C, Glaubitz S, Kanjanarach T. Measuring patient satisfaction with diabetes disease state management services in community pharmacy. Res Social Adm Pharm. 2009;5(1):31-39.

19. Kassam R, Collins JB, Berkowitz J. Comparison of patients' expectations and experiences at traditional pharmacies and pharmacies offering enhanced advanced pharmacy practice experiences Am J Pharm Educ. 2010;74(5):90.

20. Bandura A. Self-efficacy: toward a unifying theory of behavioral change. Psychol Rev. 1977;84(2):191-215.

21. Cameron KA, Ross EL, Clayman ML, Bergeron AR, Federman AD, Bailey SC. Measuring patients' self-efficacy in understanding and using prescribing medication. Patient Educ Couns. 2010;80(3):372-376.
22. Wolf MS, Davis TC, Shrank W, Rapp DN, Bass PF, Connor UM, et al. To err is human: patient misinterpretations of prescription drug label instructions. Patient Educ Couns. 2007;67(3):293-300.

23. Tabachnick BG, Fidell LS. Using multivariate statistics, 5th edition. Boston; Pearson Education.

24. Herling RW. Operational definitions of expertise and competence. $A d v$ Develop Hum Resour. 2000;2(1):8-21.

25. Crosby L, Evans K, Cowles D. Relationship quality in services selling: an interpersonal influence perspective. J Mark. 1990;54(3):68-81.

26. Wagner D, Bear M. Patient satisfaction with nursing care: a concept analysis within a nursing framework. J Adv Nurs. 2009;65(3): 692-701.

27. Heidegger T, Saal D, Nuebling M. Patient satisfaction with anaesthesia care: what is patient satisfaction, how should it be measured, and what is the evidence for assuring high patient satisfaction? Best Pract Res Clin Anaesthesiol. 2006;20(2):331-346.

28. Gourley GK, Gourley DR, La Monica Rigolosi E, Reed P, Solomon DK, Washington E. Development and validation of the pharmaceutical care satisfaction questionnaire. Am J Manag Care. 2001;7(5):461-466.

29. Kenny DA. Mediation. http://davidakenny.net/cm/mediate.htm. Accessed April 7th. 2012.

30. Perepelkin J. Public opinion of pharmacists and pharmacist prescribing. Can Pharm J. 2011;144(2):86-93.

31. Krueger JL, Hermansen-Kobulnicky CJ. Patient perspective of medication information desired and barriers to asking pharmacists questions. J Am Pharm Assoc. 2011;51(4):510-519.

32. Thom DH, Campbell B. Patient-physician trust: an exploratory study. J Fam Pract. 1997;44(2):169-176.

33. Kim SS, Kaplowitz S, Johnston MV. The effects of physician empathy on patient satisfaction and compliance. Eval Health Prof. 2004;27(3):237-251.

34. Lee YY, Lin JL. The effects of trust in physician on self-efficacy, adherence and diabetes outcomes. Social Sci Med. 2009;68(6):1060-1068.

35. Keshishian F, Colodny N, Boone RT. Physician-patient and pharmacistpatient communication: Geriatrics' perceptions and opinions. Patient Educ Couns. 2008;71(2):265-284.

36. Berry LL, Parish JT, Janakiraman R, Ogburn-Russel L, Couchman GR, Rayburn WL. Patients' commitment to their primary physician and why it matters. Ann Fam Med. 2008;6(1):6-13.

37. Gabel L, Lucas J, Westbury RC. Why do patients continue to see the same physician? Fam Pract Res J. 1993;13(2):133-147. 


\section{Appendix I}

1. How long have you been coming to the pharmacy?
a) This is my first time
b) 0-6 months
c) 6 months -1 year
d) 1-5 years
e) Other:

\begin{tabular}{|l|c|c|c|}
\hline $\begin{array}{l}\text { 2. How often do you expect your pharmacist to check } \\
\text { that your prescription medication: }\end{array}$ & Never & Sometimes & Always \\
\hline & (1) & (2) & (3) \\
\hline a) Is accurate? & & & \\
\hline b) Is for my condition? & & & \\
\hline c) Will work for me? & & & \\
\hline d) Is safe for me? & & & \\
\hline e) Is one I want to take? & & & \\
\hline
\end{tabular}

\begin{tabular}{|l|c|c|c|c|}
\hline \multirow{2}{*}{$\begin{array}{l}\text { Tell me if you agree or disagree with the following } \\
\text { items (adapted from Cameron et al): }{ }^{21}\end{array}$} & $\begin{array}{c}\text { Strongly } \\
\text { disagree }\end{array}$ & $\begin{array}{c}\text { Slightly } \\
\text { disagre }\end{array}$ & $\begin{array}{c}\text { Slightly } \\
\text { agree }\end{array}$ & $\begin{array}{c}\text { Strongly } \\
\text { agree }\end{array}$ \\
\cline { 2 - 5 } & $(1)$ & $(2)$ & $(3)$ & (4) \\
\hline 3. It is easy for me to take my medicine on time & & & & \\
\hline 4. It is easy to remember to take all my medicines & & & & \\
\hline $\begin{array}{l}\text { 5. It is easy for me to set a schedule to take my } \\
\text { medicines each day }\end{array}$ & & & & \\
\hline 6. It is easy for take my medicines every day & & & & \\
\hline $\begin{array}{l}\text { 7. It is easy for me to ask pharmacist questions } \\
\text { about my medicine }\end{array}$ & & & & \\
\hline $\begin{array}{l}\text { 8. It is easy for me to understand my pharmacist's } \\
\text { instructions for my medicine }\end{array}$ & & & & \\
\hline $\begin{array}{l}\text { 9. It is easy for me to understand instructions on } \\
\text { medicine bottles }\end{array}$ & & & & \\
\hline $\begin{array}{l}\text { 10. It is easy for me to get all the information } \\
\text { I need about my medicine }\end{array}$ & & & & \\
\hline
\end{tabular}

11. How old are you?
a) 18-25 years
b) 26-35 years
c) $36-45$ years
d) $46-55$ years
e) 56-65 years
f) $66-75$ years
g) $\geq 76$ years 


\begin{tabular}{|c|c|c|c|c|c|}
\hline \multirow[t]{2}{*}{$\begin{array}{l}\text { Here is what I would expect in any pharmacy } \\
\text { (adapted from Kassam et al): }{ }^{14}\end{array}$} & $\begin{array}{l}\text { Strongly } \\
\text { disagree }\end{array}$ & Disagree & Neutral & Agree & $\begin{array}{c}\text { Strongly } \\
\text { agree }\end{array}$ \\
\hline & (1) & (2) & (3) & (4) & (5) \\
\hline \multicolumn{6}{|l|}{$\begin{array}{l}\text { 12. Between pharmacy visits, I expect } \\
\text { pharmacists to phone and ask me if my } \\
\text { new medicines are working }\end{array}$} \\
\hline \multicolumn{6}{|l|}{$\begin{array}{l}\text { 13. I expect pharmacists to develop a specific } \\
\text { plan with me to solve any drug-related problems }\end{array}$} \\
\hline \multicolumn{6}{|l|}{$\begin{array}{l}\text { 14. I expect pharmacists to ask me questions } \\
\text { about my existing medical conditions }\end{array}$} \\
\hline \multicolumn{6}{|l|}{$\begin{array}{l}\text { 15. I expect pharmacists to ask me about } \\
\text { vitamins and other health products }\end{array}$} \\
\hline \multicolumn{6}{|l|}{$\begin{array}{l}\text { 16. I expect pharmacists to ask me questions } \\
\text { about the various medicines I take }\end{array}$} \\
\hline \multicolumn{6}{|l|}{$\begin{array}{l}\text { 17. I expects pharmacists to explain how each } \\
\text { of my medicines is supposed to help me }\end{array}$} \\
\hline \multicolumn{6}{|l|}{$\begin{array}{l}\text { 18. I expect pharmacists to work with my doctor } \\
\text { and me to ensure I am on the right medicines }\end{array}$} \\
\hline \multicolumn{6}{|l|}{$\begin{array}{l}\text { 19. I expect pharmacists to explain to me how } \\
\text { to know for sure if my medication is working }\end{array}$} \\
\hline \multicolumn{6}{|l|}{$\begin{array}{l}\text { 20. I expect pharmacy staff to be pleasant } \\
\text { and courteous to me }\end{array}$} \\
\hline \multicolumn{6}{|l|}{$\begin{array}{l}\text { 21. I expect reasonable privacy when I discuss } \\
\text { my health issues with a pharmacist }\end{array}$} \\
\hline \multicolumn{6}{|l|}{$\begin{array}{l}\text { 22. I expect pharmacists to ask me if I have } \\
\text { any concerns about my medicines }\end{array}$} \\
\hline \multicolumn{6}{|l|}{$\begin{array}{l}\text { 23. I expect pharmacists to explain what to do } \\
\text { in case I have side effects from my medicines }\end{array}$} \\
\hline \multicolumn{6}{|l|}{$\begin{array}{l}\text { 24. When I pick up my new prescriptions, } \\
\text { I expect to talk to a pharmacist }\end{array}$} \\
\hline \multicolumn{6}{|l|}{$\begin{array}{l}\text { 25. I expect pharmacists to make notes in the } \\
\text { computer about how my medicines are working }\end{array}$} \\
\hline $\begin{array}{l}\text { 26. When I pick up my refills, I expect to } \\
\text { talk to a pharmacist }\end{array}$ & & & & & \\
\hline
\end{tabular}




\begin{tabular}{|c|c|c|c|c|c|}
\hline \multirow[t]{2}{*}{$\begin{array}{l}\text { Here is what I have experienced recently in this } \\
\text { pharmacy (adapted from Kassam et al): }:^{14}\end{array}$} & $\begin{array}{l}\text { Strongly } \\
\text { disagree }\end{array}$ & Disagree & Neutral & Agree & $\begin{array}{l}\text { Strongly } \\
\text { agree }\end{array}$ \\
\hline & (1) & (2) & (3) & (4) & (5) \\
\hline \multicolumn{6}{|l|}{$\begin{array}{l}\text { 27. Between pharmacy visits, a pharmacist phoned } \\
\text { and asked me if my new medicines are working }\end{array}$} \\
\hline \multicolumn{6}{|l|}{$\begin{array}{l}\text { 28. Pharmacists developed a specific plan with } \\
\text { me to solve any drug-related problems }\end{array}$} \\
\hline \multicolumn{6}{|l|}{$\begin{array}{l}\text { 29. Pharmacists asked me questions about } \\
\text { my existing medical conditions }\end{array}$} \\
\hline \multicolumn{6}{|l|}{$\begin{array}{l}\text { 30. Pharmacists asked me about vitamins } \\
\text { and other health products }\end{array}$} \\
\hline \multicolumn{6}{|l|}{$\begin{array}{l}\text { 31. Pharmacists asked me questions about } \\
\text { the various medicines I take }\end{array}$} \\
\hline \multicolumn{6}{|l|}{$\begin{array}{l}\text { 32. Pharmacists explained how each of } \\
\text { my medicines is supposed to help me }\end{array}$} \\
\hline \multicolumn{6}{|l|}{$\begin{array}{l}\text { 33. Pharmacists worked with my doctor and } \\
\text { me to ensure I am on the right medicines }\end{array}$} \\
\hline \multicolumn{6}{|l|}{$\begin{array}{l}\text { 34. Pharmacists explained to me how to } \\
\text { know for sure if my medication is working }\end{array}$} \\
\hline \multicolumn{6}{|l|}{$\begin{array}{l}\text { 35. Pharmacy staff was pleasant and } \\
\text { courteous to me }\end{array}$} \\
\hline \multicolumn{6}{|l|}{$\begin{array}{l}\text { 36. I had reasonable privacy when I discussed } \\
\text { my health issues with a pharmacist }\end{array}$} \\
\hline \multicolumn{6}{|l|}{$\begin{array}{l}\text { 37. Pharmacists asked me if I have any concerns } \\
\text { about my medicines }\end{array}$} \\
\hline \multicolumn{6}{|l|}{$\begin{array}{l}\text { 38. Pharmacists explained what to do in case } \\
\text { I have side effects from my medicines }\end{array}$} \\
\hline \multicolumn{6}{|l|}{$\begin{array}{l}\text { 39. When I pick up my new prescriptions, } \\
\text { I talked to a pharmacist }\end{array}$} \\
\hline \multicolumn{6}{|l|}{$\begin{array}{l}\text { 40. Pharmacists made notes in the computer } \\
\text { about my how medicines are working }\end{array}$} \\
\hline $\begin{array}{l}\text { 41. When I pick up my refills, I talked } \\
\text { to a pharmacist }\end{array}$ & & & & & \\
\hline
\end{tabular}




\begin{tabular}{|c|c|c|c|c|c|}
\hline \multirow[t]{2}{*}{$\begin{array}{l}\text { Here are my thoughts about the pharmacist(s) } \\
\text { at this store (adapted from Worley and Schommer): }{ }^{9}\end{array}$} & $\begin{array}{l}\text { Strongly } \\
\text { disagree }\end{array}$ & Disagree & Neutral & Agree & $\begin{array}{l}\text { Strongly } \\
\text { agree }\end{array}$ \\
\hline & (1) & (2) & (3) & (4) & $(5)$ \\
\hline \multicolumn{6}{|l|}{$\begin{array}{l}\text { 42. My pharmacist is a knowledgeable source } \\
\text { of prescription drug information }\end{array}$} \\
\hline \multicolumn{6}{|l|}{$\begin{array}{l}\text { 43. My pharmacist is able to answer all of } \\
\text { my medication questions }\end{array}$} \\
\hline \multicolumn{6}{|l|}{$\begin{array}{l}\text { 44. My pharmacist is knowledgeable about potential } \\
\text { side effects that my medication may cause }\end{array}$} \\
\hline \multicolumn{6}{|l|}{$\begin{array}{l}\text { 45. My pharmacist is able to explain how to take } \\
\text { medications correctly }\end{array}$} \\
\hline \multicolumn{6}{|l|}{ 46. My pharmacist is trustworthy } \\
\hline \multicolumn{6}{|l|}{$\begin{array}{l}\text { 47. I trust that my pharmacist will alert my physician } \\
\text { of any problems with the combination of drugs } \\
\text { that I am taking, or any allergies that I have }\end{array}$} \\
\hline \multicolumn{6}{|l|}{$\begin{array}{l}\text { 48. There are times when my pharmacist } \\
\text { seems insincere (reverse coded) }\end{array}$} \\
\hline \multicolumn{6}{|l|}{ 49. My pharmacist always put my best interests first } \\
\hline \multicolumn{6}{|l|}{$\begin{array}{l}\text { 50. I always leave my pharmacy satisfied } \\
\text { with the pharmacist }\end{array}$} \\
\hline \multicolumn{6}{|l|}{$\begin{array}{l}\text { 51. I always leave my pharmacy feeling that I have } \\
\text { received useful information about } \\
\text { my medications from my pharmacist }\end{array}$} \\
\hline \multicolumn{6}{|l|}{ 52. I value the services that my pharmacist provides me } \\
\hline \multicolumn{6}{|l|}{$\begin{array}{l}\text { 53. I am grateful for the individualized attention } \\
\text { that I receive from my pharmacist }\end{array}$} \\
\hline \multicolumn{6}{|l|}{$\begin{array}{l}\text { 54. It is important to me to take my prescription } \\
\text { to the same pharmacist or group of pharmacists, } \\
\text { whenever I need a prescription filled }\end{array}$} \\
\hline \multicolumn{6}{|l|}{$\begin{array}{l}\text { 55. If I had a general health related question that } \\
\text { did not require me to obtain a prescription, I } \\
\text { could still rely on my pharmacist for advice } \\
\text { related to these matters }\end{array}$} \\
\hline $\begin{array}{l}\text { 56. If a less expensive pharmacy opened near } \\
\text { my present pharmacist, I would change } \\
\text { pharmacies (reverse coded) }\end{array}$ & & & & & \\
\hline
\end{tabular}

57. How long do you expect to wait for one prescription to be prepared? minutes

58. How long do you expect to talk about one prescription with a pharmacist? minutes

Patient Preference and Adherence

\section{Publish your work in this journal}

Patient Preference and Adherence is an international, peer-reviewed, open access journal focusing on the growing importance of patient preference and adherence throughout the therapeutic continuum. Patient satisfaction, acceptability, quality of life, compliance, persistence and their role in developing new therapeutic modalities and compounds to optimize clinical outcomes for existing disease states are major areas of interest. This journal has been accepted for indexing on PubMed Central. The manuscript management system is completely online and includes a very quick and fair peer-review system. Visit http://www.dovepress.com/ testimonials.php to read real quotes from published authors. 